\title{
openheart Serial assessment of the index of microcirculatory resistance during primary percutaneous coronary intervention comparing manual aspiration catheter thrombectomy with balloon angioplasty (IMPACT study): a randomised controlled pilot study
}

\author{
Stephen P Hoole, ${ }^{1}$ Catherine Jaworski, ${ }^{1}$ Adam J Brown, ${ }^{1}$ Liam M McCormick, ${ }^{1}$ \\ Bobby Agrawal, ${ }^{2}$ Sarah C Clarke, ${ }^{1}$ Nick E J West ${ }^{1}$
}

To cite: Hoole SP,

Jaworski C, Brown AJ, et al. Serial assessment of the index of microcirculatory resistance during primary percutaneous coronary intervention comparing manual aspiration catheter thrombectomy with balloon angioplasty (IMPACT study): a randomised controlled pilot study. Open Heart 2015;2: 000238. doi:10.1136/openhrt-2015000238

Received 7 January 2015 Revised 13 March 2015 Accepted 31 March 2015

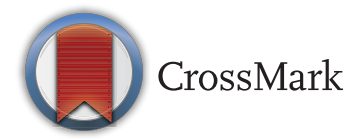

${ }^{1}$ Department of Interventional Cardiology, Papworth Hospital, Cambridge, UK ${ }^{2}$ Department of Radiology, Papworth Hospital, Cambridge, UK

Correspondence to Dr Stephen P Hoole; stephen.hoole@papworth. nhs.uk

\section{ABSTRACT}

Objective: Utilising a novel study design, we evaluated serial measurements of the index of microcirculatory resistance (IMR) in patients undergoing primary percutaneous coronary intervention (PPCI) for STsegment elevation myocardial infarction (STEMI) to assess the impact of device therapy on microvascular function, and determine what proportion of microvascular injury is related to the PPCI procedure, and what is an inevitable consequence of STEMI.

Design: 41 patients undergoing PPCI for STEMI were randomised to balloon angioplasty $(B A, n=20)$ or manual thrombectomy (MT, $n=21$ ) prior to stenting. Serial IMR measurements, corrected for collaterals, were recorded at baseline and at each stage of the procedure. Microvascular obstruction (MVO) and infarct size at $24 \mathrm{~h}$ and 3 months were measured by troponin and cardiac MRI (CMR).

Results: IMR did not change significantly following $\mathrm{PPCl}$, but patients with lower IMR values $(<32, \mathrm{n}=30)$ at baseline had a significant increase in IMR following PPCl (baseline: $21.2 \pm 7.9$ vs post-stent: $33.0 \pm 23.7$, $\mathrm{p}=0.01$ ) attributable to prestent IRA instrumentation (baseline: $21.7 \pm 8.0$ vs post-BA or MT: $36.9 \pm 25.9$, $\mathrm{p}=0.006$ ). Post-stent IMR correlated with early MVO on CMR $(p=0.01)$. There was no significant difference in post-stent IMR, presence of early MVO or final infarct size between patients with BA and patients treated with MT.

Conclusions: Patients with STEMI and less microcirculatory dysfunction may be susceptible to acute iatrogenic microcirculatory injury from prestent coronary devices. MT did not appear to be superior to $\mathrm{BA}$ in maintaining microcirculatory integrity when the guide wire partially restores IRA flow during PPCl.

Trial registration number: ISRCTN31767278.

\section{KEY QUESTIONS}

What is already known about this subject? The use of manual thrombectomy (MT) in primary percutaneous coronary intervention (PPCl) for ST-segment elevation myocardial infarction (STEMI) is recommended in the guidelines, but there are little data to guide case selection. The recent publication of TASTE by Fröbert and colleagues question the benefit of indiscriminate MT on long-term mortality following PPCI treatment. Limited mechanistic data were presented by these investigators to explain the neutrality of MT, and the accompanying editorial highlighted a need for further research. It is not known whether the use of MT in certain subgroups is deleterious or if a more targeted use of MT is appropriate.

\section{What does this study add?}

Our data provide interesting mechanistic insight to help interpret the findings observed in TASTE. We caution against the indiscriminate use of MT for all PPCI. Our randomised pilot study uses a novel methodological design: serial pressure wirederived index of microcirculatory resistance (IMR) to temporally assess the microcirculation at intervals during $\mathrm{PPCl}$. This provides novel insights into the changes occurring in microcirculatory function during $\mathrm{PPCl}$ and for the first time allows the response of the microcirculation to coronary instrumentation to be studied. It appears that in patients with less microcirculatory dysfunction at presentation and spontaneous restoration of coronary flow in the infarct-related artery, prestent device treatment is detrimental, raising the IMR and contributing to downstream microcirculatory injury. 


\section{KEY QUESTIONS}

How might this impact on clinical practice?

Our study, for the first time, attempts to understand which stages of the PPCI procedure are beneficial and which may be detrimental or have a neutral effect. This will inevitably allow streamlining of interventional coronary procedures and improve PPCI safety and cost-effectiveness to ultimately benefit patients with STEMI.

\section{BACKGROUND}

Distal embolisation of the thrombus during primary percutaneous coronary intervention (PPCI) may contribute to no-reflow, and this is deleterious. ${ }^{1}$ Manual thrombectomy (MT) has emerged as a potential therapy to reduce the thrombus burden prior to direct stenting (DS). MT is thought to reduce the risk of angiographically assessed microcirculatory dysfunction post-PPCI, ${ }^{2}$ particularly in those with a high thrombotic burden. ${ }^{3}{ }^{34}$ Although the TAPAS study reported a mortality benefit attributed to $\mathrm{MT}^{5}$ this has not been confirmed in the substantially larger TASTE study. ${ }^{6}$ In addition, the INFUSE-AMI study failed to demonstrate a reduction in infarct size in patients randomised to $\mathrm{MT}^{7}$ raising concerns regarding the efficacy of unselected MT use in all ST-segment elevation myocardial infarction (STEMI).

The index of microcirculatory resistance (IMR) is a validated measure of microcirculatory function that can be calculated during PPCI, ${ }^{8}$ and has been shown to predict final infarct size and left ventricular (LV) function in patients with STEMI. ${ }^{9} 10$ This wire-based technology enables serial measurement of the temporal changes in microcirculatory resistance at each stage of the coronary intervention in the same patient. This offers unique insights into the effect on the coronary microcirculation of instrumentation of an infarct-related artery (IRA) and, importantly, determines whether MT relieves or contributes to the final microcirculatory dysfunction seen in STEMI.

We aimed to investigate whether MT would change microvascular function measured by IMR, compared with balloon angioplasty (BA), and were particularly interested to observe IMR in susceptible individuals with less microcirculatory dysfunction at baseline.

\section{METHODS}

Patients presenting with STEMI via the PPCI pathway between February 2012 and March 2013 at a single specialist cardiothoracic centre were considered for inclusion in the study. Inclusion criteria were: (1) age at enrolment $>18$ and $<90$ years, (2) ability to give informed consent, (3) ECG-confirmed STEMI (ST elevation $\geq 2 \mathrm{~mm}$ in $\geq 2$ contiguous chest leads or $\geq 1 \mathrm{~mm}$ in $\geq 2$ contiguous limb leads) or new left bundle branch block (LBBB), (4) chest pain for $<12 \mathrm{~h}$ and (5) restoration of at least thrombolysis in myocardial infarction (TIMI) 1 flow after the guide wire crossed the coronary occlusion. Exclusion criteria were: (1) cardiogenic shock, (2) previous MI in the IRA territory, (3) unfavourable anatomy (left main occlusion or distal vessel occlusion), (4) severe asthma or bradycardia precluding use of adenosine, (5) women of childbearing age, (6) life expectancy <3 months. Consenting patients were randomised to MT or BA prior to coronary angiography, by sealed envelope allocation prepared by an independent Research and Development Unit.

\section{PROCEDURAL DETAILS}

PPCI was performed via the radial or femoral arterial approach using $6 \mathrm{Fr}$ guiding catheters. A $6 \mathrm{Fr}$ femoral venous sheath was inserted and a multipurpose catheter positioned into the right atrium for central venous administration of adenosine and assessment of central venous pressure $\left(\mathrm{P}_{\mathrm{v}}\right)$.

All patients received aspirin $300 \mathrm{mg}$ and clopidogrel $600 \mathrm{mg}$ preloading in the ambulance en route to the PPCI centre. Patients were anticoagulated with a heparin bolus (70-100 U/kg) after arterial sheath insertion to achieve an activated clotting time (ACT) $>250 \mathrm{~s}$. Adjunctive pharmacotherapy, including abciximab (Reopro, Eli Lilly, Indianapolis, Indiana, USA) and bivalirudin (The Medicines Company, Parsippany, New Jersey, USA), was given at the operator's discretion. Iopromide (Ultravist, Bayer HealthCare Pharmaceuticals, Leverkusen, Germany) was used as the contrast agent for all cases.

Angiographic variables were assessed independently by two interventional cardiologists blinded to treatment allocation. Pre-PPCI angiographic collateral assessment was performed using the modified Rentrop score. ${ }^{11}$ TIMI flow score was assessed at baseline, after initial wiring of the IRA and at the end of the procedure, as previously described. ${ }^{12}$ TIMI thrombus grade (TG) was also evaluated after the wire passage had restored flow. ${ }^{13}$ In those receiving MT, the presence of an aspirated thrombus was documented. Complete ST-segment elevation resolution (STR $>70 \%$ ) was assessed by comparing the 90 min post-PPCI ECG with baseline ECG.

MT catheter selection was at the operator's discretion; in 18/21 (86\%), the EXPORT AP (Medtronic, Minneapolis, Minnesota, USA) manual thrombus aspiration catheter was used in accordance with the manufacturers' information for use (IFU). It was mandated that the catheter crossed the culprit lesion, that aspiration started before crossing, and that $2 \times 20 \mathrm{~mL}$ syringes of coronary blood were aspirated from the culprit vessel. All patients in the MT group then had direct stenting (DS). Those randomised to BA had predilation using a $2.0 \times 15 \mathrm{~mm}$ Emerge balloon (Boston Scientific, Natick, Massachusetts, USA) inflated to $8 \mathrm{~atm}$ for $20 \mathrm{~s}$ at the site of occlusion prior to stent deployment. There was no crossover between groups.

\section{INDEX OF MICROCIRCULATORY RESISTANCE}

A Certus PressureWire (St Jude Medical, Minnesota, USA) was calibrated to atmospheric pressure before 

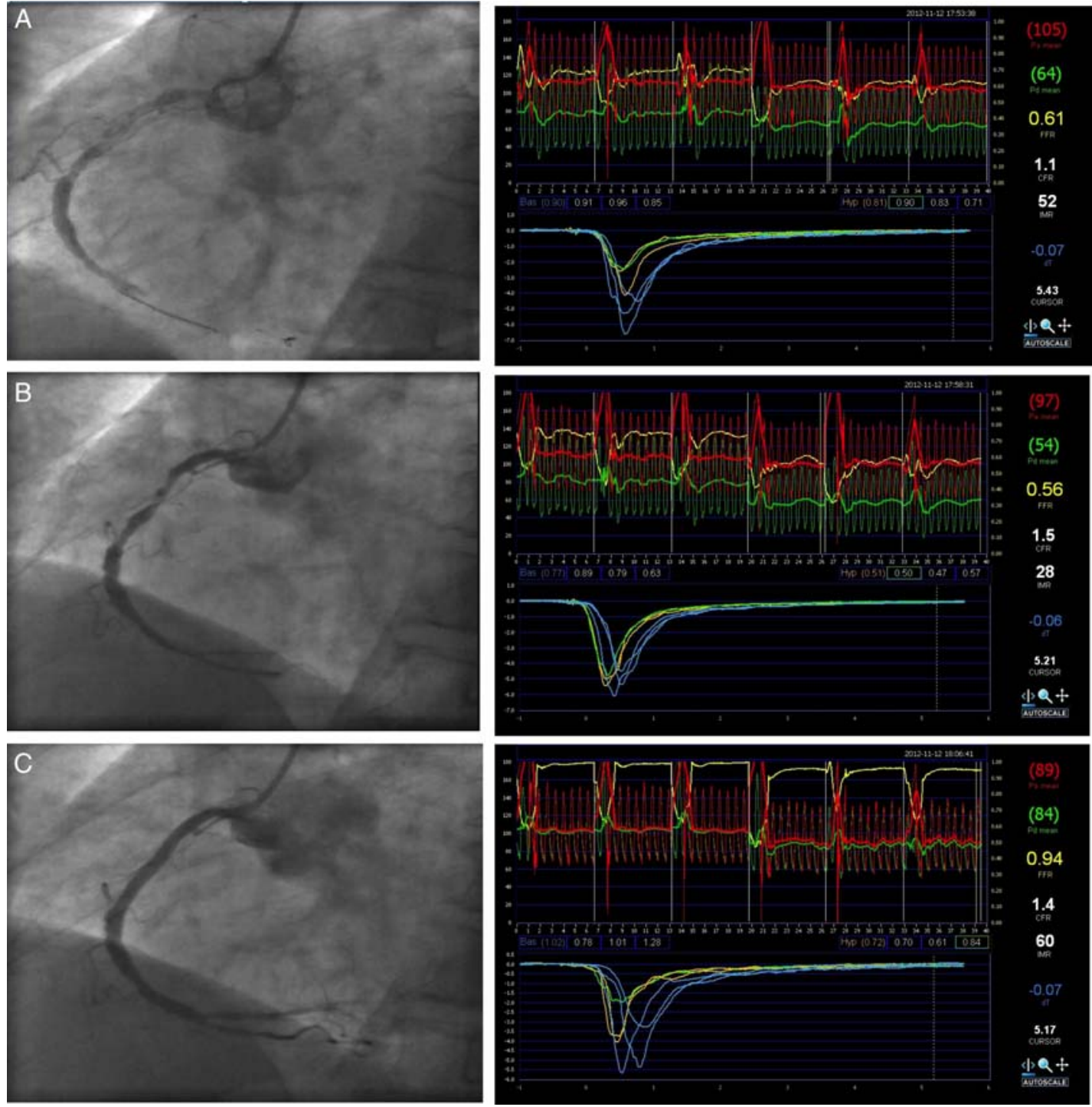

Figure 1 Example of an index of microcirculatory resistance (IMR) data set at $(\mathrm{A})$ baseline, $(\mathrm{B})$ after manual thrombectomy (MT) and (C) after direct stent deployment.

insertion and then advanced to the tip of the guiding catheter where aortic and wire pressures were equalised. The wire was then advanced distally in the IRA, with the pressure transducer positioned in the distal third of the culprit vessel in a segment free from adjacent side branches, and this position was maintained throughout the study. A $0.2 \mathrm{mg}$ bolus of intracoronary glyceryl trinitrate was administered, and once steady state was achieved, the baseline coronary pressure and flow measurements were measured. The latter was derived from the reciprocal of transit time $\left(\mathrm{T}_{\mathrm{mn}}\right)$ of an intracoronary injectate of room-temperature saline (thermodilution technique) as previously described. ${ }^{14-17}$ Coronary microcirculatory hyperaemia was induced by intravenous administration of adenosine $0.14 \mathrm{mg} / \mathrm{kg} / \mathrm{min}$ into the femoral vein. At maximal hyperaemia, $\mathrm{T}_{\mathrm{mn}}$, aortic $\left(\mathrm{P}_{\mathrm{a}}\right)$ and coronary distal $\left(\mathrm{P}_{\mathrm{d}}\right)$ pressures were recorded. Coronary wedge pressure $\left(\mathrm{P}_{\mathrm{w}}\right)$ was measured separately as $P_{d}$ during the first occlusive balloon inflation. At the end of the procedure, the pressure wire was withdrawn to the coronary ostium to enable pressure-drift correction of $\mathrm{P}_{\mathrm{d}}$ as necessary.

These measurements enabled the calculation of uncorrected, apparent $\operatorname{IMR}_{(\text {app })}=\mathrm{P}_{\mathrm{d}} \times\left(\mathrm{T}_{\mathrm{mn}}\right)_{\text {hyperaemia, }}$ IMR $=\mathrm{P}_{\mathrm{a}} \times \mathrm{T}_{\mathrm{mn}} \times\left(\left(\mathrm{P}_{\mathrm{d}}-\mathrm{P}_{\mathrm{w}}\right) /\left(\mathrm{P}_{\mathrm{a}}-\mathrm{P}_{\mathrm{w}}\right)\right)_{\text {hyperaemia }}$ corrected for collaterals, ${ }^{18}$ fractional flow reserve $(\mathrm{FFR})=\left(\mathrm{P}_{\mathrm{d}}-\mathrm{P}_{\mathrm{v}}\right) /$ $\left(\mathrm{P}_{\mathrm{a}}-\mathrm{P}_{\mathrm{v}}\right)_{\text {hyperaemia, }}$ coronary flow reserve $(\mathrm{CFR})=$ $\left(\mathrm{T}_{\mathrm{mn}}\right)_{\text {baseline }} /\left(\mathrm{T}_{\mathrm{mn}}\right)_{\text {hyperaemia }}$ and collateral flow index by pressure $\left(\mathrm{CFI}_{\mathrm{p}}\right)=\left(\mathrm{P}_{\mathrm{w}}-\mathrm{P}_{\mathrm{v}}\right) /\left(\mathrm{P}_{\mathrm{a}}-\mathrm{P}_{\mathrm{v}}\right)_{\text {baseline. Patients had }}$ coronary measurements to derive IMR at each stage of their PPCI-before intervention, after either BA or MT and finally, after stenting (figure 1).

\section{BLOOD TESTS}

Cardiac troponin-I (cTnI, Bayer ADVIA IMS Troponin-I Ultra, Leverkusen, Germany) was measured at baseline, 12 and $24 \mathrm{~h}$. 
CARDIAC MRI

Cardiac MRI (CMR) studies were performed using a 1.5 T CMR scanner (Magnetom Avanto, Siemens AG, Erlangen, Germany) within $48 \mathrm{~h}$ of PPCI and at 3 months follow-up. Image stacks were acquired using standard protocols. Both 'early' (following first pass perfusion) and 'late' (5-10 min later) enhancement images were acquired using gadolinium (Gadovist, Bayer Pharma AG, Berlin) at $0.2 \mathrm{~mL} / \mathrm{kg}$. Hypoenhanced areas represent microvascular obstruction (MVO), ${ }^{19}$ and early gadolinium enhancement is a more sensitive means of identifying $\mathrm{MVO} .{ }^{20} \mathrm{CMR}$ data were analysed offline by two blinded CMR experts (CJ and BA) using semiautomated CMR42 software (Circle Cardiovascular Imaging, Alberta, Canada) to enable LV volumetric analysis and wall motion score index calculation. Early and late MVO were recorded as binary measurements, and the infarct size was quantified.

\section{CLINICAL FOLLOW-UP}

In hospital, 30-day and 6-month major adverse cardiovascular event (MACE) rates, defined as death from any cause or MI, were recorded.

\section{SPECIFIC OBJECTIVES}

The primary objective of the study was to compare serial IMR measurements between patients randomised to PPCI with and without manual thrombectomy. Secondary end points were to assess: (1) the effect of coronary instrumentation on IMR in patients with less microcirculatory dysfunction at baseline and (2) the effect of reperfusion strategy on infarct size (measured by serial cTnI and CMR late gadolinium enhancement (LGE)), MVO and LV function measured by CMR.

The local research ethics committee approved the study protocol (LREC references 08/H0306/49), and the study conformed to the principles outlined in the Declaration of Helsinki. The trial was registered on the International Standard Randomised Controlled Trial Number register (ISRCTN31767278).

\section{STATISTICAL METHODS AND ANALYSIS}

Sample size was informed by previous studies; a clinically important difference was the $20 \%$ reduction in IMR in the MT group, equating to an IMR difference of 8 $(\mathrm{SD}=8, \alpha=0.05$ and power $=0.80)$ and requiring a total sample size of 40. A subanalysis examining patients with a lower index of microvascular resistance at presentation $(\mathrm{IMR}<32)$ was prespecified.

Continuous variables are summarised as mean (SD) or median (Q1-Q3) unless otherwise stated. Paired data were compared by a paired Student $t$ test, and independent data were compared with a non-paired Student $t$ test, or a Mann-Whitney-Wilcoxon test was used when appropriate. Categorical data are expressed as numbers (percentages) and compared by use of Fisher's exact test. A two-sided value of $p<0.05$ was considered significant. The authors had full access to and take full responsibility for the integrity of the data. All authors have read and agree to the manuscript as written.

\section{RESULTS}

Sixty-three patients were approached, of whom 56 were eligible, consented and were recruited into the study (figure 2). Two patients screened did not fulfil the ECG criteria, three had experienced symptoms $>12 \mathrm{~h}$ and two refused consent. A further 15 patients were subsequently excluded after randomisation due to TIMI 0 flow after passage of a guide wire through the lesion $(n=9)$, technical problems $(n=3)$, anatomical factors $(n=2)$ and intraprocedural haemodynamic instability $(n=1)$. The
Figure 2 Consort flow chart of study recruitment and assessment schedule (BA, balloon angioplasty; cTnl, cardiac troponin-I; IMR, index of microcirculatory resistance; MT, manual thrombectomy; PPCI, primary percutaneous coronary intervention; STEMI, ST-segment elevation myocardial infarction; TIMI, thrombolysis in myocardial infarction).

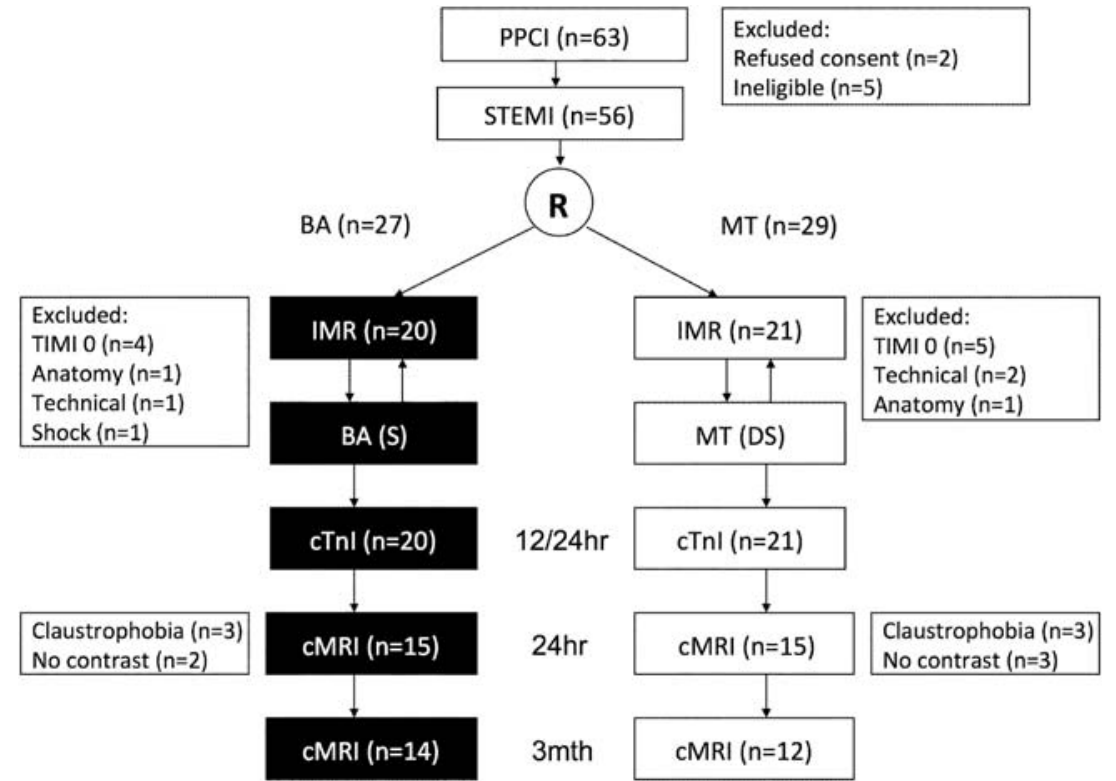


Table 1 Demographic data for each group

\begin{tabular}{llll}
\hline & BA $(\mathbf{n = 2 0})$ & MT $(\mathbf{n = 2 1 )}$ & $\mathbf{p ~ V a l u e ~}$ \\
\hline Age, years & $67.2 \pm 11.6$ & $64.9 \pm 11.2$ & 0.51 \\
Male, $\mathrm{n}(\%)$ & $15(75)$ & $16(76)$ & 1.00 \\
Creatine, $\mu \mathrm{mol} / \mathrm{L}$ & $106.2 \pm 23.0$ & $100 \pm 15.9$ & 0.32 \\
Diabetes, $\mathrm{n}(\%)$ & $3(15)$ & $5(24)$ & 0.70 \\
BMI, $\mathrm{kg} / \mathrm{m}^{2}$ & $28.0 \pm 4.4$ & $27.9 \pm 4.1$ & 0.96 \\
Hypertension, $\mathrm{n}(\%)$ & $9(45)$ & $8(38)$ & 0.76 \\
Current/ex-smoker, $\mathrm{n}(\%)$ & $13(65)$ & $12(57)$ & 0.75 \\
Non-IRA MI, $\mathrm{n}(\%)$ & $1(5)$ & $0(0)$ & 0.49 \\
Total cholesterol, mmol/L & $5.4 \pm 1.2$ & $5.1 \pm 1.1$ & 0.51 \\
Prior statin use, $\mathrm{n}(\%)$ & $4(20)$ & $3(14)$ & 0.70 \\
\hline BA, balloon angioplasty; BMI, body mass index; IRA, infarct-related artery; MI, myocardial infarction; MT, manual thrombectomy.
\end{tabular}

remaining 41 participants (20 in the BA group and 21 in the MT group) were included in the analysis.

Both groups were well matched with similar patient demographics (table 1). Importantly, both groups also had similar procedural data (table 2), with acceptable door-to-device times despite additional protocol-driven IMR measurements. Ischaemic time (IT) was not significantly different between the groups, although there was a trend to a longer IT in the BA group. Surrogates for area of myocardium at risk (IRA, proximity of the culprit lesion, wall motion score index and presence of angiographic collaterals) were similar. Surrogate markers of procedural complexity, for example, fluoroscopy time and contrast dose, were also not significantly different, but there was a trend towards greater complexity in the BA group. Procedures were predominantly performed via a radial approach and adjunctive pharmacotherapy was administered in approximately half of both groups. Drug eluting stents of similar length and calibre were deployed. TIMI flow and TIMI thrombus grade at baseline were similar between groups, with macroscopic evidence of thrombus retrieval in 15 patients $(71 \%)$ of the MT group.

Baseline coronary haemodynamics, including IMR and $\mathrm{CFI}_{\mathrm{p}}$-assessed collateralisation to the IRA, were similar between the two groups, although there was a trend to higher baseline IMR in the BA group. Post-PPCI IMR was not significantly different to baseline (baseline: $35.6 \pm 31.8$ vs post-stent: $40.8 \pm 30.9$, $\mathrm{p}=0.26$ ), nor was there any difference between groups treated with MT and BA (table 3 and figure 3A). STR and final TIMI flow were also similar.

Subgroup analysis of post-stent IMR limited to those patients with less microvascular dysfunction at baseline (IMR $<32, n=30,15$ in each group) revealed a significant deterioration in IMR for the cohort (baseline: $21.2 \pm 7.9$ vs post-stent: $33.0 \pm 23.7, \mathrm{p}=0.01$ ), and a similar trend in IMR increase post-PPCI for each device (MT prestent: $20.3 \pm 7.3$ vs post-stent: $33.1 \pm 26.1, \mathrm{p}=0.07$; $\mathrm{BA}$ prestent: $22.1 \pm 8.6$ vs post-stent: $32.8 \pm 22.1, \quad \mathrm{p}=0.10$; $\mathrm{p}=0.98$ for intergroup comparison of final IMR) (figure 3B).

\section{Table 2 Procedural data for each group}

\begin{tabular}{|c|c|c|c|}
\hline & $B A(n=20)$ & MT $(n=21)$ & p Value \\
\hline Median IT, min & $204(144432)$ & $180(145215)$ & 0.21 \\
\hline Median DTBT, min & $34(28,41)$ & $36(31,39)$ & 0.72 \\
\hline Fluoroscopy time, $\min$ & $12.2 \pm 7.1$ & $11.2 \pm 4.7$ & 0.60 \\
\hline Contrast dose, $\mathrm{mL}$ & $196.5 \pm 81$ & $173 \pm 74$ & 0.35 \\
\hline Radial access, n (\%) & $19(95)$ & $20(95)$ & 1.00 \\
\hline Proximal LAD, n (\%) & $5(25)$ & $6(29)$ & 1.00 \\
\hline Rentrop score $0-1, \mathrm{n}(\%)$ & $18(90)$ & $18(86)$ & 1.00 \\
\hline Mean stents, $\mathrm{n}$ & $1.6 \pm 0.7$ & $1.3 \pm 0.8$ & 0.26 \\
\hline DES, n (\%) & $17(85)$ & $18(86)$ & 1.00 \\
\hline Stent length, mm & $33.4 \pm 17.3$ & $32.3 \pm 19.4$ & 0.84 \\
\hline Stent diameter, $\mathrm{mm}$ & $3.1 \pm 0.6$ & $3.1 \pm 0.9$ & 0.90 \\
\hline Reopro/bivalirudin, n (\%) & $10(50)$ & $13(62)$ & 0.54 \\
\hline TIMI TG $\geq 2, n(\%)$ & $14(70)$ & $14(67)$ & 1.00 \\
\hline TIMI 2/3 pre, n (\%) & $5(25)$ & $6(29)$ & 1.00 \\
\hline TIMI 2/3 post, n (\%) & $20(100)$ & $21(100)$ & 1.00 \\
\hline STR $\geq 70 \%, n(\%)$ & $9(45)$ & $10(48)$ & 1.00 \\
\hline
\end{tabular}


Table 3 Comparison of the pre- $\mathrm{PCl}$ and post- $\mathrm{PCl}$ coronary haemodynamics in the BA and stent and MT and stent groups (pre- $\mathrm{PCl}$ vs post- $\mathrm{PCl}$ values: $\uparrow \mathrm{p}<0.0001$; $\neq \mathrm{p}<0.05)$

\begin{tabular}{|c|c|c|c|}
\hline & $B A(n=20)$ & MT $(n=21)$ & p Value \\
\hline \multicolumn{4}{|l|}{ Pre-PCl } \\
\hline $\mathrm{P}_{\mathrm{d}}, \mathrm{mm} \mathrm{Hg}$ & $48.8 \pm 19.9$ & $44.6 \pm 16.8$ & 0.47 \\
\hline $\mathrm{P}_{\mathrm{a}}, \mathrm{mm} \mathrm{Hg}$ & $89.4 \pm 18.3$ & $85.9 \pm 21.3$ & 0.58 \\
\hline $\mathrm{P}_{\mathrm{w}}, \mathrm{mm} \mathrm{Hg}$ & $22.8 \pm 12.1$ & $17.7 \pm 11.0$ & 0.17 \\
\hline $\mathrm{T}_{\mathrm{mn}}, \mathrm{s}$ & $1.5 \pm 0.9$ & $1.3 \pm 0.9$ & 0.44 \\
\hline $\mathrm{IMR}_{(\mathrm{app})}$ & $65.3 \pm 45.9$ & $51.6 \pm 35.7$ & 0.29 \\
\hline IMR & $40.7 \pm 40.7$ & $30.7 \pm 20.0$ & 0.32 \\
\hline FFR & $0.54 \pm 0.20$ & $0.53 \pm 0.20$ & 0.72 \\
\hline CFR & $1.04 \pm 0.56$ & $1.14 \pm 0.52$ & 0.56 \\
\hline $\mathrm{CFI}_{\mathrm{p}}$ & $0.19 \pm 0.11$ & $0.14 \pm 0.11$ & 0.16 \\
\hline \multicolumn{4}{|l|}{ Post-PCl } \\
\hline $\mathrm{P}_{\mathrm{d}}, \mathrm{mm} \mathrm{Hg}$ & $80.4 \pm 20.4 \dagger$ & $81.6 \pm 19.7 \dagger$ & 0.85 \\
\hline $\mathrm{P}_{\mathrm{a}}, \mathrm{mm} \mathrm{Hg}$ & $84.3 \pm 21.8$ & $84.9 \pm 19.7$ & 0.93 \\
\hline $\mathrm{T}_{\mathrm{mn}}, \mathrm{s}$ & $0.6 \pm 0.4 †$ & $0.5 \pm 0.3 \dagger$ & 0.66 \\
\hline $\mathrm{IMR}_{(\mathrm{app})}$ & $44.6 \pm 36.3 \ddagger$ & $43.3 \pm 30.1$ & 0.90 \\
\hline IMR & $41.6 \pm 34.1$ & $40.1 \pm 28.5$ & 0.88 \\
\hline FFR & $0.96 \pm 0.04 \dagger$ & $0.96 \pm 0.06 \dagger$ & 0.63 \\
\hline CFR & $1.27 \pm 0.56$ & $1.43 \pm 0.71$ & 0.43 \\
\hline \multicolumn{4}{|c|}{$\begin{array}{l}\mathrm{BA} \text {, balloon angioplasty; } \mathrm{CFI}_{\mathrm{p}} \text {, pressure-derived collateral flow } \\
\text { index; CFR, coronary flow reserve; FFR, fractional flow reserve; } \\
\text { IMR( }(\mathrm{app}) \text {, apparent IMR without correction for collaterals; IMR, } \\
\text { index of microcirculatory resistance; } \mathrm{MT} \text {, manual thrombectomy; } \\
\mathrm{P}_{\mathrm{a}} \text {, aortic pressure; } \mathrm{P}_{\mathrm{d}} \text {, distal coronary pressure; } \mathrm{P}_{\mathrm{w}} \text {, coronary } \\
\text { wedge pressure during balloon occlusion; } \mathrm{PCI} \text {, percutaneous } \\
\text { coronary intervention; } \mathrm{T}_{\mathrm{mn}} \text {, transit time. }\end{array}$} \\
\hline
\end{tabular}

Serial assessment of IMR in the overall study cohort revealed that both MT and BA resulted in a comparable, small and non-significant increase in IMR before stenting (pre-MT: $30.8 \pm 20.0$ vs post-MT: 33.1 $\pm 20.5, \mathrm{p}=0.59$; pre-BA: $40.7 \pm 40.7$ vs post-BA: $45.4 \pm 40.0$, $\mathrm{p}=0.37 ; \mathrm{p}=0.18$ for intergroup comparison of postdevice IMR). However, in the IMR $<32$ subgroup, any IRA instrumentation with MT or BA prior to stenting resulted in a highly significant increase in IMR (baseline: $21.7 \pm 8.0$ vs postdevice: $36.9 \pm 25.9, \mathrm{p}=0.006)$. This accounted for all the procedure-related microvascular injuries, as there was no further IMR increase poststenting. Both devices caused equivalent increases in IMR (figure 3B).

cTnI concentration was comparable between groups at baseline (cTnI, ng/L: MT $2350 \pm 8660$ vs BA $3760 \pm 6850$, $\mathrm{p}=0.63)$ and at $24 \mathrm{~h}(\mathrm{cTnI}, \mathrm{ng} / \mathrm{L}$ : MT $22670 \pm 13250$ vs BA $27650 \pm 12490, p=0.30$ ), although again there was a trend to higher levels in the BA group. CMR data at $24 \mathrm{~h}$ were available in 30 patients, and confirmed that MVO, infarct size assessed by LGE and LV function were not significantly different between the two groups. There was a trend to smaller infarct size in the group treated with MT (table 4). Patients with early MVO had a higher post-PCI IMR (no early MVO: $24.6 \pm 17.4$ vs early MVO: $50.2 \pm 36.3, \mathrm{p}=0.01)$, but those with late MVO did not have significantly higher post-PCI IMR (no late MVO: $38.9 \pm 28.4$ vs late MVO: $53.8 \pm 37.3, \mathrm{p}=0.30$ ).
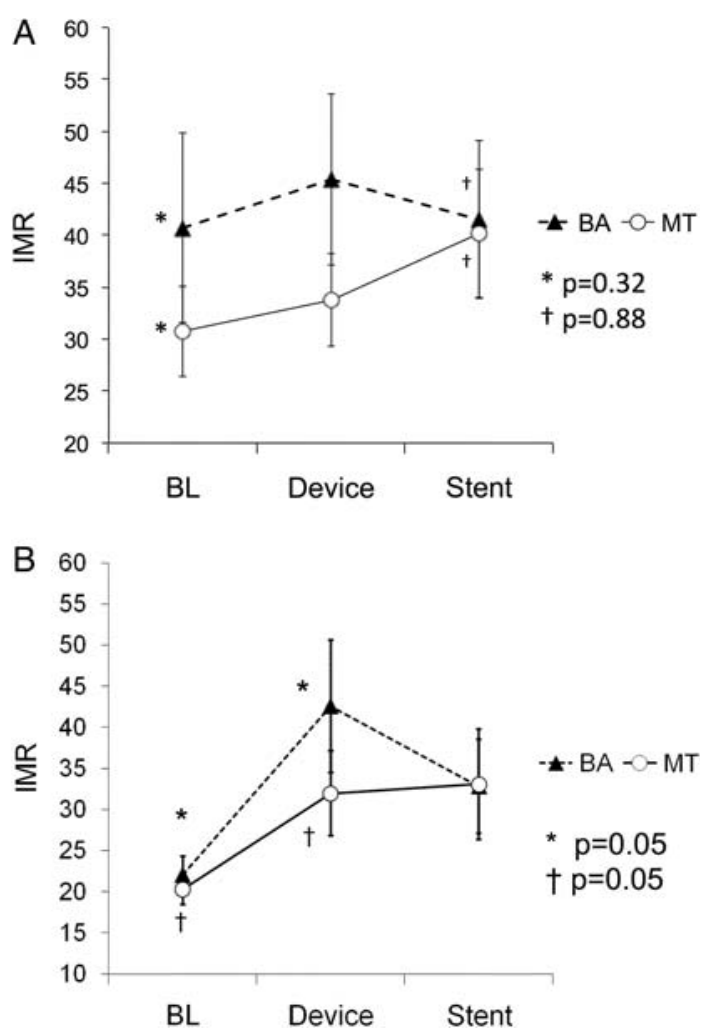

Figure 3 Comparison of the change in index of microcirculatory resistance (IMR) at each stage of the primary percutaneous coronary intervention (PPCl) for balloon angioplasty (and stent; balloon angioplasty (BA)) and manual thrombectomy (and direct stent; manual thrombectomy (MT)) for the whole group $(A)$ and $(B)$ restricted to individuals with a baseline IMR $<32$ (values mean and SEM).

Data from the CMR follow-up at 3 months were consistent with the $24 \mathrm{~h}$ CMR findings.

There was one sudden cardiac death in each group at 6-month follow-up.

\section{DISCUSSION}

We have designed a novel method of investigating the dynamic nature of microcirculatory function during

Table 4 CMR data for each group

\begin{tabular}{llll}
\hline CMR (24 $\mathbf{~})$ & BA $(\mathbf{n = 1 5 )}$ & MT $(\mathbf{n = 1 5 )}$ & $\mathbf{p}$ Value \\
\hline LVEDV, $\mathrm{mL}$ & $156 \pm 42$ & $152 \pm 23$ & 0.28 \\
LVSV, $\mathrm{mL}$ & $67 \pm 25$ & $81 \pm 21$ & 0.76 \\
LVEF, \% & $43.6 \pm 12.1$ & $52.8 \pm 11.0$ & 0.20 \\
LV mass, g & $132.9 \pm 30.6$ & $133.0 \pm 46.5$ & 0.59 \\
WMSI & $1.64 \pm 0.37$ & $1.43 \pm 0.27$ & 0.30 \\
Early MVO, $\mathrm{n}(\%)$ & $13(87)$ & $8(53)$ & 0.11 \\
Late MVO, $\mathrm{n}(\%)$ & $9(60)$ & $4(27)$ & 0.14 \\
Infarct size, g & $20.2 \pm 13.4$ & $15.1 \pm 13.1$ & 0.11 \\
Infarct size, \% LV & $14.4 \pm 7.7$ & $10.7 \pm 7.5$ & 0.11
\end{tabular}

BA, balloon angioplasty; CMR, cardiac MRI; LV, left ventricle; LVEDV, left ventricular end diastolic volume; LVEF, left ventricular ejection fraction; LVSV, left ventricular stroke volume; MT, manual thrombectomy; MVO, microvascular obstruction; WMSI, wall motion score index. 
PPCI. We have shown that in patients with partial restoration of flow in the IRA after passage of a guide wire, both MT and BA result in similar final IMR values, and may even contribute to microvascular injury in those with relatively normal IMR at presentation.

Distal embolisation is believed to contribute to no-reflow in PPCI for STEMI, resulting in reduced myocardial perfusion, infarct extension and impaired prognosis. ${ }^{121}$ MT would therefore seem intuitively beneficial and has been endorsed by current guidelines ${ }^{22}{ }^{23}$ based on published data and a recent meta-analysis. ${ }^{24}$ The largest contributor to this meta-analysis was the TAPAS trial. ${ }^{2}$ This study demonstrated an improvement in TIMI flow and myocardial blush grades in those randomised to MT, translating to a lower mortality and MI benefit at 1 year. $^{5}$ The EXPIRA trial also reported a particular advantage of using MT in those with a high clot burden (thrombus score $\geq 3$ and TIMI $0 / 1$ flow at baseline). ${ }^{4}$ However, the large INFUSE-AMI trial failed to demonstrate a reduction in infarct size at 30 days in those receiving $\mathrm{MT}^{7}$ and the appropriately powered TASTE study $^{6}$ failed to confirm a mortality benefit of MT. The mechanistic reasons for the neutral effect of MT have not been reported. Either MT use needs to be targeted more appropriately to be effective or its therapeutic utility is negligible. As much as $80 \%$ of the total clot burden quantified by optical coherence tomography (OCT) remains in the IRA following $\mathrm{MT}^{25}$ and the persistent risk of distal embolisation despite, or possible attributable to, MT remains a concern.

The IMR is an invasive measure of microcirculatory function that can be calculated during PPCI. ${ }^{8}$ IMR is known to predict final infarct size and LV function in patients with STEMI. ${ }^{9}{ }^{10}$ It is independent of epicardial stenosis severity when collateral flow is accounted for within the IMR calculation, as used in this study. ${ }^{18} 26$ Therefore, relief of the epicardial obstruction by PPCI should not result in a change in IMR, unless microparticulate matter is liberated during the procedure. This wire-based technology enables serial measurement of changes in microcirculatory resistance at each stage of the coronary intervention, offering a unique opportunity to study the effects of coronary instrumentation on the coronary microcirculation during PPCI. Importantly, this approach can determine if MT or BA relieves or contributes to the final microcirculatory dysfunction seen in STEMI.

Our study failed to demonstrate any improvement in microcirculatory function with adjunctive coronary instrumentation prior to stenting; the MT-treated group had an equivalent final IMR to those treated with simple BA. We predefined a subgroup with less microcirculatory dysfunction at baseline (IMR $<32)$, shown to be an independent predictor of smaller final infarct size, myocardial salvage and LV functional recovery following STEMI. ${ }^{9} 1027$ This group may be particularly susceptible to iatrogenic microcirculatory injury during PPCI. In these patients, both MT and BA appeared to contribute to, rather than prevent, further acute microcirculatory injury. These findings fit well with observations that Doppler wire high-intensity transitory signals, indicative of distal embolisation, occur during any mechanical instrumentation of the coronary artery. ${ }^{28}$ Our data suggest that a 'minimum touch' strategy to treat the culprit lesion may be optimal. Direct stenting without prior coronary instrumentation other than the passage of a guide wire has been shown to lower the incidence of microcirculatory injury, infarct size and mortality in STEMI. ${ }^{29}{ }^{30}$ However, when partial reflow does not occur after passage of a guide wire, coronary angiography fails to guide precise stent implantation, and MT or BA may still be necessary.

\section{CLINICAL IMPLICATIONS}

Our data suggest that the universal use of MT in all PPCI is inappropriate. In patients with STEMI, spontaneous restoration of IRA flow and relatively preserved microcirculatory function in MT and BA appear to have a deleterious effect on microcirculation.

\section{STUDY LIMITATIONS}

This is a small, single-centre pilot study utilising a novel methodological design, but it has several limitations. Our data should be viewed as hypothesis generating and requires further confirmation in larger studies.

There was an unexpected high variability in IMR between individuals that may have led to a type II error when comparing groups with MT and BA. However, serial data from the same individual remain valid. Second, despite designing a randomised controlled trial, the two groups may have been different. There was a trend to a longer IT in the group with BA and the baseline IMR was higher, and this may have contributed to the trend to more MVO and larger infarcts seen in this group. Third, the study methodology restricted our conclusions to STEMI with partial restoration of flow after wiring of the culprit lesion, as flow is required to obtain baseline transit times and IMR, and, as a result, the thrombus burden was modest. Our findings are not applicable to STEMI with a large thrombus burden. Finally, BA was performed with a balloon smaller than the reference vessel diameter, to minimise potential distal embolisation. BA with larger balloons may be inferior to MT.

\section{CONCLUSIONS}

Patients with STEMI and less microcirculatory dysfunction may be susceptible to acute iatrogenic microcirculatory injury from prestent coronary devices. MT did not appear to be superior to BA in maintaining microcirculatory integrity when the guide wire partially restores IRA flow during PPCI.

Acknowledgements The authors would like to thank all the patients and staff of Papworth Hospital NHS Foundation Trust who took part in this study. 
Contributors SPH and NEJW designed, recruited, analysed the data and wrote the manuscript. CJ and BA analysed the MRI data. AJB and SCC both recruited patients into the study. All authors read, offered edits and agree to the manuscript's final draft.

Funding This study was funded by the NIHR Cambridge Biomedical Research Centre.

Competing interests None declared.

Patient consent Obtained.

Ethics approval Cambridgeshire 3 REC: 08/H0306/49.

Provenance and peer review Not commissioned; externally peer reviewed.

Open Access This is an Open Access article distributed in accordance with the Creative Commons Attribution Non Commercial (CC BY-NC 4.0) license, which permits others to distribute, remix, adapt, build upon this work noncommercially, and license their derivative works on different terms, provided the original work is properly cited and the use is non-commercial. See: http:// creativecommons.org/licenses/by-nc/4.0/

\section{REFERENCES}

1. Jaffe R, Charron T, Puley G, et al. Microvascular obstruction and the no-reflow phenomenon after percutaneous coronary intervention. Circulation 2008;117:3152-6.

2. Svilaas T, Vlaar PJ, van der Horst IC, et al. Thrombus aspiration during primary percutaneous coronary intervention. $N$ Engl J Med 2008;358:557-67.

3. Burzotta F, Trani C, Romagnoli E, et al. Manual thrombus-aspiration improves myocardial reperfusion: the randomized evaluation of the effect of mechanical reduction of distal embolization by thrombus-aspiration in primary and rescue angioplasty (REMEDIA) trial. J Am Coll Cardiol 2005;46:371-6.

4. Sardella G, Mancone M, Bucciarelli-Ducci C, et al. Thrombus aspiration during primary percutaneous coronary intervention improves myocardial reperfusion and reduces infarct size: the EXPIRA (thrombectomy with export catheter in infarct-related artery during primary percutaneous coronary intervention) prospective, randomized trial. J Am Coll Cardiol 2009;53:309-15.

5. Vlaar PJ, Svilaas T, van der Horst IC, et al. Cardiac death and reinfarction after 1 year in the Thrombus Aspiration during Percutaneous coronary intervention in Acute myocardial infarction Study (TAPAS): a 1-year follow-up study. Lancet 2008;371:1915-20.

6. Frobert O, Lagerqvist B, Olivecrona GK, et al. Thrombus aspiration during ST-segment elevation myocardial infarction. N Engl J Med 2013;369:1587-97.

7. Stone GW, Maehara A, Witzenbichler B, et al. Intracoronary abciximab and aspiration thrombectomy in patients with large anterior myocardial infarction: the INFUSE-AMI randomized trial. JAMA 2012:307:1817-26.

8. Fearon WF, Balsam LB, Farouque HM, et al. Novel index for invasively assessing the coronary microcirculation. Circulation 2003;107:3129-32.

9. Fearon WF, Shah M, Ng M, et al. Predictive value of the index of microcirculatory resistance in patients with ST-segment elevation myocardial infarction. J Am Coll Cardiol 2008;51:560-5.

10. McGeoch R, Watkins S, Berry $\mathrm{C}$, et al. The index of microcirculatory resistance measured acutely predicts the extent and severity of myocardial infarction in patients with ST-segment elevation myocardial infarction. JACC Cardiovasc Interv 2010;3:715-22.

11. Rentrop KP, Cohen M, Blanke $\mathrm{H}$, et al. Changes in collateral channel filling immediately after controlled coronary artery occlusion by an angioplasty balloon in human subjects. J Am Coll Cardiol 1985;5:587-92.
12. Chesebro $\mathrm{JH}$, Knatterud $\mathrm{G}$, Roberts $\mathrm{R}$, et al. Thrombolysis in Myocardial Infarction (TIMI) Trial, Phase I: a comparison between intravenous tissue plasminogen activator and intravenous streptokinase. Circulation 1987;76:142-54.

13. Gibson CM, de Lemos JA, Murphy SA, et al. Combination therapy with abciximab reduces angiographically evident thrombus in acute myocardial infarction: a TIMl 14 substudy. Circulation 2001;103:2550-4.

14. De Bruyne B, Pijls NH, Smith L, et al. Coronary thermodilution to assess flow reserve: experimental validation. Circulation 2001;104:2003-6.

15. Fearon WF, Farouque HM, Balsam LB, et al. Comparison of coronary thermodilution and Doppler velocity for assessing coronary flow reserve. Circulation 2003;108:2198-200.

16. Pijls NH, De Bruyne B, Smith L, et al. Coronary thermodilution to assess flow reserve: validation in humans. Circulation 2002;105:2482-6.

17. Barbato E, Aarnoudse W, Aengevaeren WR, et al. Validation of coronary flow reserve measurements by thermodilution in clinical practice. Eur Heart J 2004;25:219-23.

18. Fearon WF, Aarnoudse W, Pijls NH, et al. Microvascular resistance is not influenced by epicardial coronary artery stenosis severity: experimental validation. Circulation 2004;109:2269-72.

19. Wu KC. CMR of microvascular obstruction and hemorrhage in myocardial infarction. J Cardiovasc Magn Reson 2012;14:68.

20. Bekkers SC, Yazdani SK, Virmani R, et al. Microvascular obstruction: underlying pathophysiology and clinical diagnosis. J Am Coll Cardiol 2010;55:1649-60.

21. Brosh D, Assali AR, Mager A, et al. Effect of no-reflow during primary percutaneous coronary intervention for acute myocardial infarction on six-month mortality. Am J Cardiol 2007;99:442-5

22. Steg PG, James SK, Atar D, et al. ESC Guidelines for the management of acute myocardial infarction in patients presenting with ST-segment elevation. Eur Heart J 2012;33:2569-619.

23. O'Gara PT, Kushner FG, Ascheim DD, et al. 2013 ACCF/AHA guideline for the management of ST-elevation myocardial infarction: executive summary: a report of the American College of Cardiology Foundation/American Heart Association Task Force on Practice Guidelines. Circulation 2012;127:529-55.

24. Kumbhani DJ, Bavry AA, Desai MY, et al. Role of aspiration and mechanical thrombectomy in patients with acute myocardial infarction undergoing primary angioplasty: an updated meta-analysis of randomized trials. J Am Coll Cardiol 2013;62:1409-18

25. Onuma $\mathrm{Y}$, Thuesen L, van Geuns RJ, et al. Randomized study to assess the effect of thrombus aspiration on flow area in patients with ST-elevation myocardial infarction: an optical frequency domain imaging study-TROFI trial. Eur Heart J 2013;34:1050-60.

26. Yong AS, Ho M, Shah MG, et al. Coronary microcirculatory resistance is independent of epicardial stenosis. Circ Cardiovasc Interv 2012;5:103-8, S1-2.

27. Cuculi F, Dall'Armellina E, Manlhiot C, et al. Early change in invasive measures of microvascular function can predict myocardial recovery following $\mathrm{PCl}$ for ST-elevation myocardial infarction. Eur Heart J 2014;35:1971-80.

28. Okamura A, Ito H, Iwakura K, et al. Clinical implications of distal embolization during coronary interventional procedures in patients with acute myocardial infarction: quantitative study with Doppler guidewire. JACC Cardiovasc Interv 2008;1:268-76.

29. Loubeyre $\mathrm{C}$, Morice MC, Lefevre $\mathrm{T}$, et al. A randomized comparison of direct stenting with conventional stent implantation in selected patients with acute myocardial infarction. J Am Coll Cardiol 2002;39:15-21.

30. Mockel M, Vollert J, Lansky AJ, et al. Comparison of direct stenting with conventional stent implantation in acute myocardial infarction. Am J Cardiol 2011;108:1697-703. 